Grundlagen der Biographik 


\section{Grundlagen der Biographik}

Theorie und Praxis des biographischen Schreibens

Herausgegeben von Christian Klein

Verlag J.B. Metzler

Stuttgart $\cdot$ Weimar 
Die Deutsche Bibliothek - CIP-Einheitsaufnahme

Ein Titeldatensatz für diese Publikation ist bei Der Deutschen Bibliothek erhältlich

ISBN 978-3-476-01904-2

ISBN 978-3-476-02884-6 (eBook)

DOI 10.1007/978-3-476-02884-6

Dieses Werk einschließlich aller seiner Teile ist urheberrechtlich geschützt.JedeVerwertung außerhalb der engen Grenzen des Urheberrechtsgesetzes ist ohne Zustimmung desVerlages unzulässig und strafbar. Das gilt insbesondere fürVervielfältigungen, Übersetzungen, Mikroverfilmungen und die Einspeicherung und Verarbeitung in elektronischen Systemen.

(C) 2002 Springer-Verlag GmbH Deutschland

Ursprünglich erschienen bei J.B. Metzlersche Verlagsbuchhandlung

und Carl Ernst Poeschel Verlag GmbH in Stuttgart 2002

www.metzlerverlag.de

info@metzlerverlag.de 


\section{Inhaltsverzeichnis}

Einleitung: Biographik zwischen Theorie und Praxis.

Versuch einer Bestandsaufnahme

Christian Klein

Mode ohne Methode? Überlegungen zu einer Theorie der literaturwissenschaftlichen Biographik

Peter-André Alt

Korrespondenzen und Konstellationen. Zum postalischen Prinzip biographischer Darstellungen ....

Sigrid Weigel

Das Leben - buchstäblich. Über neuere Biographik und

Geschichtswissenschaft

Ulrich Raulff

Lebensbeschreibung als Lebenserschreibung?

Vom Nutzen biographischer Ansätze aus der Soziologie für

die Literaturwissenschaften

Christian Klein

Autoren auf der Couch? Psychopathologie, Psychoanalyse und biographisches Schreiben

Thomas Anz

(Nietzsche), die Genealogie, die Biographie

Giorgi Maisuradze

Geschlechterdifferenz in der literaturwissenschaftlichen Biographik.

Ein Forschungsprogramm

Anita Runge

Netzlebenslinien. Probleme der Biographie im digitalen Zeitalter

David Oels, Stephan Porombka

Literarische Deutungen eines Lebens und biographische Interpretationen eines Textes: Der Tod in Venedig in Thomas-Mann-Biographien

Gary Schmidt

Strategien des Verschweigens. Über die Tabuisierung der Homosexualität Federico García Lorcas während der Franco-Zeit 159

Werner Altmann 
VI Inhaltsverzeichnis

Zur Rolle des Biographen. Erfahrungen beim Schreiben

einer Biographie

Hermann Kurzke

Werkreflexion, Stichwort: literarische Biographie

179

Dieter Kühn

"Wir wollen jetzt Geschichten erzählen...»

Sander L. Gilman über seine Jurek-Becker-Biographie, Biographik in

Deutschland und den USA. Ein Gespräch mit Christian Klein

Rechtsfragen des Biographieschreibens.

Teil 1: Recherche

Andreas von Arnauld

Rechtsfragen des Biographieschreibens

Teil 2: Publikation

Andreas von Arnauld

Auswahlbibliographie

Die Autorinnen und Autoren

Register (Namen und Begriffe) 